\title{
Dual-wavelength aerosol vertical profile measurements by MAX-DOAS at Tsukuba, Japan
}

\author{
H. Irie $^{1}$, Y. Kanaya ${ }^{1}$, H. Akimoto ${ }^{1}$, H. Iwabuchi ${ }^{1}$, A. Shimizu ${ }^{2}$, and K. Aoki ${ }^{3}$ \\ ${ }^{1}$ Frontier Research Center for Global Change, Japan Agency for Marine-Earth Science and Technology, 3173-25 \\ Showa-machi, Kanazawa-ku, Yokohama, Kanagawa 236-0001, Japan \\ ${ }^{2}$ National Institute for Environmental Studies, 16-2, Onogawa, Tsukuba, Ibaraki 305-8506, Japan \\ ${ }^{3}$ Department of Earth Science, Faculty of Sciences, University of Toyama, 3190 Gofuku, Toyama 930-8555, Japan
}

Received: 1 August 2008 - Published in Atmos. Chem. Phys. Discuss.: 14 November 2008

Revised: 16 March 2009 - Accepted: 20 April 2009 - Published: 24 April 2009

\begin{abstract}
We present vertical profiles of the aerosol extinction coefficient retrieved from ground-based Multi-Axis Differential Optical Absorption Spectroscopy (MAX-DOAS) measurements at Tsukuba, Japan $\left(36.1^{\circ} \mathrm{N}, 140.1^{\circ} \mathrm{E}\right)$, from November 2006 to March 2007. Retrievals utilizing absorption by the oxygen collision complex $\mathrm{O}_{4}$ are first made at two wavelengths, 354 and $476 \mathrm{~nm}$. A robust assessment of the MAX-DOAS aerosol data is then made using coincident lidar measurements throughout the period. Agreement between aerosol extinction coefficients measured by MAXDOAS and the lidar tends to be better at the longer wavelength and at lower altitudes. At $476 \mathrm{~nm}$, the best agreement, to within $30 \%$, is found at altitudes of $0-1 \mathrm{~km}$, confirming results from a literature assessment for a two-month measurement period. These findings are supported by comparisons between aerosol optical depths derived from MAX-DOAS and sky radiometer measurements and are further explained by differences in the altitude-dependent measurement sensitivity to the aerosol extinction coefficient between 354 and $476 \mathrm{~nm}$. Thus, uncertainty in MAX-DOAS aerosol measurements is well quantified and characterized, providing a basis for quantitative studies using MAX-DOAS measurements.
\end{abstract}

\section{Introduction}

Atmospheric aerosol particles are recognized as an important contributor to climate change, but the magnitude of their radiative forcing as well as its sign is highly uncertain (IPCC,

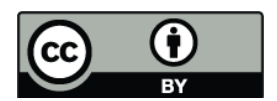

Correspondence to: $\mathrm{H}$. Irie (irie@jamstec.go.jp)
2007). To measure the aerosol vertical profile in the lower troposphere, a new remote sensing technique using MultiAxis Differential Optical Absorption Spectroscopy (MAXDOAS) has been proposed recently (Wagner et al., 2004; Frieß et al., 2006; Irie et al., 2008a, b). MAX-DOAS has several technical advantages for the purpose of atmospheric monitoring, including simple setup, low power consumption, and fully automated operation without absolute radiometric calibration. Another notable advantage of MAX-DOAS is the capability for simultaneous measurements of aerosols and gases, including nitrogen dioxide $\left(\mathrm{NO}_{2}\right)$, formaldehyde ( $\mathrm{HCHO})$, glyoxal $(\mathrm{CHOCHO})$, and sulphur dioxide $\left(\mathrm{SO}_{2}\right)$ (e.g., Hönninger et al., 2004; Wittrock et al., 2004; Heckel et al., 2005; Hendrick et al., 2006; Leigh et al., 2006; Sinreich et al., 2007; Inomata et al., 2008; Irie et al., 2008b), which may play direct or indirect roles in determining chemical, physical, and optical properties of aerosols. Thus, it is expected that MAX-DOAS measurements would contribute to both the monitoring and a better understanding of atmospheric composition changes, in which aerosols play an important role. The quantitative assessment of MAX-DOAS aerosol measurements, however, has been very limited.

The present study is a follow-on to that of Irie et al. (2008a), who first reported ground-based MAX-DOAS measurements of the vertical profile of the aerosol extinction coefficient at a single wavelength of $476 \mathrm{~nm}\left(k_{476}\right)$ at Tsukuba, Japan $\left(36.1^{\circ} \mathrm{N}, 140.1^{\circ} \mathrm{E}, 29 \mathrm{~m}\right.$ a.s.1.), from 1 November to 21 December 2006. They concluded that the overall uncertainties of MAX-DOAS $k_{476}$ values at $0-1$ and $1-2 \mathrm{~km}$ are better than $30 \%$ and $60 \%$, respectively, based on comparisons with other established aerosol measurements by lidar and sky radiometer, although part of the differences found in the comparisons should have been caused by the

Published by Copernicus Publications on behalf of the European Geosciences Union. 


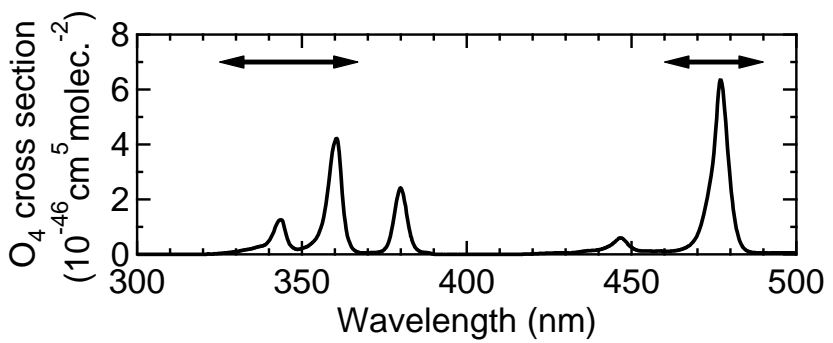

Fig. 1. Absorption cross section of $\mathrm{O}_{4}$. Two windows, at 325367 and $460-490 \mathrm{~nm}$, indicated by arrows, are analyzed for aerosol retrieval at 354 and $476 \mathrm{~nm}$, respectively.

sampling of different air masses. Here we analyze measurements for a time period of more than double the duration of the initial study, from 1 November 2006 until 16 March 2007, to confirm the uncertainty estimated by Irie et al. (2008a). To characterize MAX-DOAS aerosol measurements in a more robust sense, we present retrievals of the aerosol extinction coefficient at an additional, shorter wavelength, $354 \mathrm{~nm}\left(k_{354}\right)$, and discuss them together with the retrievals at $476 \mathrm{~nm}$.

\section{MAX-DOAS measurements}

We operated the MAX-DOAS system at Tsukuba, Japan, from 1 November 2006 through 16 March 2007 with the same instrumentation as described by Irie et al. (2008a). A miniaturized UV/visible spectrometer (B\&W TEK Inc., BTC111) with a charge-coupled device (CCD) was used to record spectra between 280 and $560 \mathrm{~nm}$. The measurements were made at six different elevation angles (ELs) of $3^{\circ}, 5^{\circ}, 10^{\circ}, 20^{\circ}, 30^{\circ}$, and $90^{\circ}$ using a movable mirror, which repeated the same sequence of ELs every $30 \mathrm{~min}$. The wavelength calibration using a high-resolution solar spectrum (Kurucz et al., 1984) indicated that the spectral resolution (Full Width at Half Maximum (FWHM)) was 0.40 and $0.55 \mathrm{~nm}$ at wavelengths around 354 and $476 \mathrm{~nm}$, respectively, throughout the period of the measurements.

As a next step, DOAS spectral fitting (Platt, 1994) using the nonlinear least-squares method (Irie et al., 2008a) was performed to retrieve the differential slant column density $(\triangle \mathrm{SCD})$, which is defined as the difference between the slant column density along the path of sunlight for an offaxis measurement $\left(\mathrm{EL}<90^{\circ}\right)$ and that for a zenith-sky measurement $\left(E L=90^{\circ}\right)$. Two different fitting windows, 325367 and $460-490 \mathrm{~nm}$, were analyzed for aerosol retrievals at 354 and $476 \mathrm{~nm}$, respectively. The wavelengths of 354 and $476 \mathrm{~nm}$ correspond to the $\mathrm{O}_{4}$-cross-section-weighted mean wavelengths for the respective fitting window (Fig. 1). We used the $\mathrm{O}_{4}$ absorption cross section data of Greenblatt et al. (1990) with manual adjustment (A. Richter, personal communication). Fitting parameters and qualities for the $\triangle \mathrm{SCD}$ retrievals are summarized in Table 1. Compared to 325-
Table 1. DOAS fitting parameters and quality.

\begin{tabular}{lll}
\hline Fitting window $(\mathrm{nm})$ & $460-490$ & $325-367$ \\
\hline Degree of polynomial & 3 & 3 \\
Degree of offset polynomial & 2 & 2 \\
Absorber & $\mathrm{O}_{4}, \mathrm{NO}_{2}, \mathrm{O}_{3}$ & $\mathrm{O}_{4}, \mathrm{NO}_{2}, \mathrm{O}_{3}$ \\
& $\mathrm{H}_{2} \mathrm{O}, \mathrm{Ring}$ & $\mathrm{HCHO}, \mathrm{BrO}, \mathrm{Ring}$ \\
Typical residual & 0.0007 & 0.0011 \\
Typical error in $\mathrm{O}_{4} \Delta \mathrm{SCD}^{\mathrm{a}}$ & $10 \times 10^{40}$ & $18 \times 10^{40}$ \\
$\left(\right.$ molecules $\left.^{2} \mathrm{~cm}^{-5}\right)$ & & \\
\hline
\end{tabular}

${ }^{\mathrm{a}}$ Median values for $\mathrm{SZA}=50^{\circ} \pm 5^{\circ}$.

$367 \mathrm{~nm}$, the $460-490 \mathrm{~nm}$ fitting window yields smaller $\mathrm{O}_{4}$ $\triangle \mathrm{SCD}$ errors (Table 1), likely due to the stronger $\mathrm{O}_{4}$ absorption at $460-490 \mathrm{~nm}$ (Fig. 1) and the larger air mass factor. Although in the spectra recorded with our instrument the intensity is usually stronger at $460-490 \mathrm{~nm}$ than at 325 $367 \mathrm{~nm}$, smaller errors were found at the longer wavelength even when a similar statistical comparison was made under the same intensity conditions.

Subsequently to the DOAS analysis, an aerosol retrieval algorithm employing the optimal estimation method (Rodgers, 2000; Irie et al., 2008a) was utilized to invert the $\mathrm{O}_{4} \Delta \mathrm{SCD}$ values to retrieve the vertical profiles of the aerosol extinction coefficient, $k$, for every 30-min interval. Retrievals were made at solar zenith angles (SZAs) less than $83^{\circ}$ to minimize a potential influence of the treatment of the Earth's sphericity in radiative transfer model calculations (Wagner et al., 2007). The mean $k$ for each $1-\mathrm{km}$ layer is analyzed below and denoted $k(0-1 \mathrm{~km})$ for the layer $0-1 \mathrm{~km}$, for example. This inversion method refers to the differential box air mass factor $\left(\Delta A_{\text {box }}\right)$ lookup tables (LUTs) created by a radiative transfer model, the Monte Carlo Atmospheric Radiative Transfer Simulator (MCARaTS) (Iwabuchi, 2006). $\Delta A_{\text {box }}$ is the difference between the box air mass factor $\left(A_{\text {box }}\right)$ value for off-axis measurements and that for the reference, where $A_{\mathrm{box}}$ is defined as the ratio of partial slant to vertical columns for the given layer. We prepared different LUTs for each wavelength, 354 and $476 \mathrm{~nm}$. The calculations by MCARaTS have been validated through comparisons with other radiative transfer models (Wagner et al., 2007). We assumed a single scattering albedo of 0.95 , an asymmetry parameter of 0.65 (under the Henyey-Greenstein approximation), and a surface albedo of 0.10 .

As described by Irie et al. (2008a), this aerosol retrieval algorithm uses a state vector consisting of four parameters: the aerosol optical depth $(\tau)$ and $F_{1}, F_{2}$, and $F_{3}$ values. Here the $F$ values, defined to range between 0 and 1 , are parameters determining the shape of an aerosol vertical profile. Partial $\tau$ values for layers of $0-1,1-2$, and $2-3 \mathrm{~km}$ are described as $\tau F_{1}, \tau\left(1-F_{1}\right) F_{2}$, and $\tau\left(1-F_{1}\right)\left(1-F_{2}\right) F_{3}$, respectively, and the partial $\tau$ for $3-100 \mathrm{~km}$ as $\tau\left(1-F_{1}\right)\left(1-F_{2}\right)\left(1-F_{3}\right)$. From the given partial $\tau$ above $3 \mathrm{~km}$, the profile of $k$ for a layer 

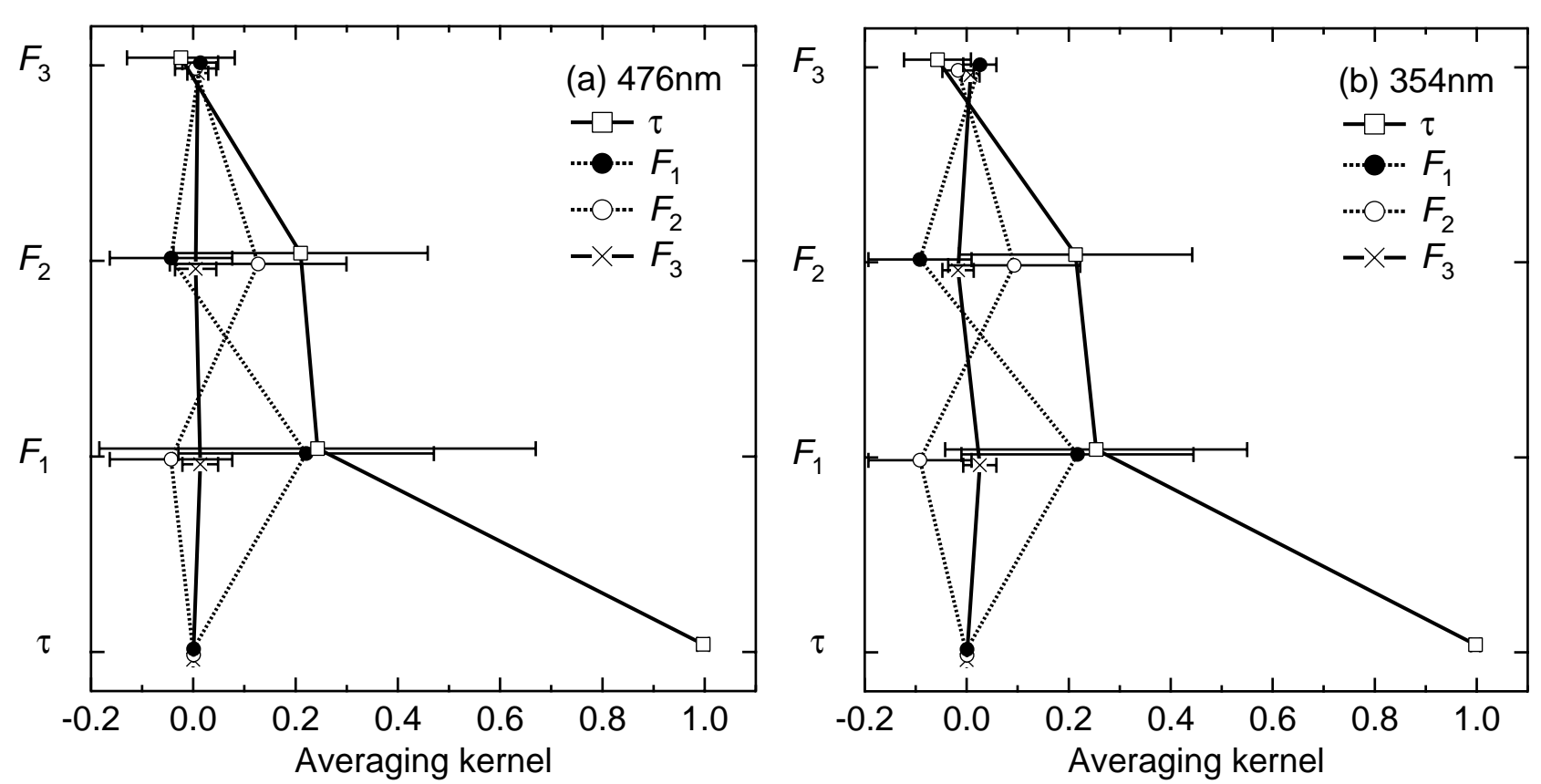

Fig. 2. Mean averaging kernels for all MAX-DOAS aerosol retrievals at (a) 476 and (b) $354 \mathrm{~nm}$. Error bars represent $1 \sigma$ standard deviations.

from 3 to $100 \mathrm{~km}$ was determined assuming a $k$ value at the top of the layer $(100 \mathrm{~km})$ and an exponential profile shape. Similarly, we determined profiles for layers of $2-3,1-2$, and $0-1 \mathrm{~km}$, completing the $k$ vertical profile from the surface to $100 \mathrm{~km}$. This parameterization was chosen because the relative variability of the profile shape, in terms of $1-\mathrm{km}$ averages, was much less than that of the absolute $k$ value (Irie et al., 2008a).

We used the a priori state vector and the a priori covariance matrix, which are identical to those constructed by Irie et al. (2008a), based on averages and standard deviations of two months of lidar data. The a priori values $( \pm$ error) used were $\tau=0.21 \pm 1.0, F_{1}=0.70 \pm 0.05, F_{2}=0.60 \pm 0.05$, and $F_{3}=0.60 \pm 0.05$, yielding a $\tau$ of $0.21, k(0-1 \mathrm{~km})$ of $0.15 \mathrm{~km}^{-1}, k(1-2 \mathrm{~km})$ of $0.04 \mathrm{~km}^{-1}$, and $k(2-3 \mathrm{~km})$ of $0.02 \mathrm{~km}^{-1}$. The errors are $\pm 1.0,+0.76 /-0.74 \mathrm{~km}^{-1}$, $+0.24 /-0.21 \mathrm{~km}^{-1}$, and $+0.11 /-0.10 \mathrm{~km}^{-1}$, respectively. Both inversions at 354 and $476 \mathrm{~nm}$ used the same a priori state vector and a priori covariance matrix. Since $k$ values are usually greater at shorter wavelengths, this provides an opportunity to confirm the dependence of the retrievals on the a priori information, as discussed later.

By sensitivity tests described by Irie et al. (2008a), the errors of $\tau, k(0-1 \mathrm{~km}), k(1-2 \mathrm{~km})$, and $k(2-3 \mathrm{~km})$ values at $476 \mathrm{~nm}$ due to the choice of a priori values and their errors were estimated to be $10 \%, 9 \%, 34 \%$, and $43 \%$, respectively, for all the retrievals presented here. Those for $354 \mathrm{~nm}$ were $10 \%, 5 \%, 40 \%$, and $41 \%$, respectively. The sums of the smoothing error and the retrieval noise error were about $7 \%$, $13 \%, 30 \%$, and $46 \%$, respectively, at both wavelengths.
Figure $2 \mathrm{a}$ and $\mathrm{b}$ show the mean averaging kernels for all the MAX-DOAS aerosol retrievals at 476 and $354 \mathrm{~nm}$, respectively. Except for $F_{3}$, the averaging kernels peak at the corresponding labels on the plot ordinates. The $\tau$ indicates the largest value, followed by $F_{1}$ and $F_{2}$. For both wavelengths, the resulting degrees of freedom for signal (Rodgers, 2000) range from 1.0 to 3.0, with averages of $1.4 \pm 0.3$, indicating that the information contents are similar. The area (Rodgers, 2000), which provides a rough measure of the fraction of the retrieval that comes from the measurements, was calculated as the sum of all elements in the averaging kernel profile weighted by the a priori error (Liu et al., 2005). The areas were 1.0, 0.2, 0.1, and 0.1 for $\tau, F_{1}, F_{2}$, and $F_{3}$, respectively, indicating that the retrieval was done by scaling the given a priori profile first, followed by changing the profile shape (Irie et al., 2008a).

It should be noted that influences of clouds have been discussed in our previous work (Irie et al., 2008a). This work indicated that MAX-DOAS aerosol measurements would be very insensitive to high-altitude clouds (above $\sim 2 \mathrm{~km}$ ) but that data for $k$ below $\sim 2 \mathrm{~km}$ and $\tau$ could suffer from a non-negligible contribution of the cloud optical depth below $\sim 2 \mathrm{~km}$. While a cloud screening method applicable to MAX-DOAS is highly desirable, the present work focuses on cloud-free cases, which have been identified by coincident lidar and sky radiometer measurements, as described below. 


\section{Lidar and sky radiometer measurements}

From 1 November 2006 to 16 March 2007, lidar and sky radiometer measurements were performed together with MAX-DOAS at the same site in Tsukuba, Japan. The lidar system operated was a compact Mie-scattering system utilizing the second harmonics of a flashlamp-pumped Nd:YAG laser $(532 \mathrm{~nm})$ as the light source (Shimizu et al., 2004). Inversion was conducted assuming a constant lidar ratio of $50 \mathrm{sr}$ throughout the period. Only cloud-free lidar aerosol extinction data, judged by the method of Shimizu et al. (2004), were used. The lidar aerosol extinction data were converted to $k_{354}$ and $k_{476}$ values, which can be compared to MAXDOAS data, using coincident measurements of the Ångström exponent $(\alpha)$ by the sky radiometer. Note that the $\alpha$ used is a columnar quantity, as described below, and may lead to a systematic bias in lidar $k_{354}$ and $k_{476}$ values, when the $\alpha$ differs from $\alpha$ for a given altitude.

The sky radiometer measured the direct solar irradiance and the distribution of radiances in the aureole region (Aoki and Fujiyoshi, 2003). The $\tau$ data at 400, 500, 675,870 , and $1020 \mathrm{~nm}$ were derived by the inversion algorithm (SKYRAD.pack, version 4.2) developed by Nakajima et al. (1996). The $\alpha$ value was estimated from the $\tau$ values at five wavelengths. Using $\alpha, \tau$ values at 354 and $476 \mathrm{~nm}$ were derived from the measured $\tau$ values at 400 and $500 \mathrm{~nm}$, respectively. It should be noted that $\tau$ at $354 \mathrm{~nm}$ was estimated using $\alpha$, which may be valid between 400 and $1020 \mathrm{~nm}$. Details of the lidar and sky radiometer measurements used in the present study are available elsewhere (Aoki and Fujiyoshi, 2003; Shimizu et al., 2004; Irie et al., 2008a).

\section{Results and discussion}

In Fig. 3 , the MAX-DOAS $k_{476}$ and $k_{354}$ values are plotted against those derived from lidar measurements for layers of $0-1$ and $1-2 \mathrm{~km}$ over the whole period of more than 4 months. The MAX-DOAS and lidar $k_{476}(0-1 \mathrm{~km})$ values agree to within 30\% for most cases (Fig. 3a), confirming the results of Irie et al. (2008a) obtained from an onlytwo-month comparison. Similarly, the MAX-DOAS $k_{476}(1-$ $2 \mathrm{~km}$ ) values generally agree with the lidar to within $60 \%$ (Fig. 3b). Since part of the differences should have been caused by the sampling of different air masses, the uncertainties of MAX-DOAS $k_{476}(0-1 \mathrm{~km})$ and $k_{476}(1-2 \mathrm{~km})$ should be smaller than $30 \%$ and $60 \%$, respectively. This will be confirmed below by comparisons with sky radiometer measurements.

The mean MAX-DOAS values for each $0.05-\mathrm{km}^{-1}$ or $0.02-\mathrm{km}^{-1}$ range of lidar data are also plotted with red symbols in Fig. 3. It can be seen from the mean MAX-DOAS data that the correlations of $k_{476}(1-2 \mathrm{~km})$ values tend to deviate from linearity at higher lidar values (Fig. 3b). On the other hand, the individual comparisons for $k_{354}(0-1 \mathrm{~km})$ val- ues show more scatter than for $k_{476}(0-1 \mathrm{~km})$, but the differences are usually less than 50\% (Fig. 3c). Although MAXDOAS and lidar $k_{354}(0-1 \mathrm{~km})$ values are correlated linearly, a linear regression analysis suggests that MAX-DOAS values are systematically smaller (slope $=0.77$ ). The same tendency is also seen in the $k_{476}(0-1 \mathrm{~km})$ comparisons (Fig. 3a), suggesting that part of the differences can be attributed to the use of a constant lidar ratio, which is a common systematic component of the uncertainty in both lidar $k$ values. Further systematic differences can occur in the $k_{354}(0-1 \mathrm{~km})$ comparisons due to the Ångström exponent $\alpha$, which was used to derive lidar $k_{354}(0-1 \mathrm{~km})$ values, although it may be valid only at wavelengths longer than $400 \mathrm{~nm}$, as mentioned above. Indeed, the $\alpha$ value derived from the sky radiometer is slightly different from that derived directly from the two wavelengths of MAX-DOAS $k(0-1 \mathrm{~km})$ values, as discussed later.

As seen in Fig. 3d, the correlations of $k_{354}(1-2 \mathrm{~km})$ show that MAX-DOAS $k_{354}(1-2 \mathrm{~km})$ at higher lidar values tends to be closer to the value calculated from the a priori $\left(0.04 \mathrm{~km}^{-1}\right)$, resulting in underestimation. This is similar to the result for the same layer at $476 \mathrm{~nm}$ (Fig. 3b). In addition, more significant underestimation of MAX-DOAS values tends to occur at $2-3 \mathrm{~km}$, resulting from the MAXDOAS $k$ data being closer to the value calculated from the a priori $\left(0.02 \mathrm{~km}^{-1}\right)$ (Fig. 4). These tendencies are further supported by the fact that a similar underestimation is seen also in the MAX-DOAS/sky radiometer comparisons of the aerosol optical depth (Fig. 5), which contains information on high-altitude aerosols.

Thus, MAX-DOAS $k$ data at higher lidar values tend to be underestimated more at higher altitudes. In addition, uncertainty in MAX-DOAS $k$ data is likely larger at shorter wavelengths, especially considering the comparison results for $k_{476}(0-1 \mathrm{~km})$ and $k_{354}(0-1 \mathrm{~km})$ shown in Fig. $3 \mathrm{a}$ and $\mathrm{c}$, respectively.

To investigate the cause of these tendencies, we plot the median $k_{354}$ and $k_{476}$ profiles retrieved from MAX-DOAS measurements for the whole period of the measurements analyzed (Fig. 6a). As we expect, $k_{354}$ values are generally greater than $k_{476}$ values, especially at altitudes below $1 \mathrm{~km}$, although we have used the same a priori information for both wavelengths. This indicates that the aerosol retrieval method employed here is less dependent on the a priori, especially below $1 \mathrm{~km}$. Indeed, errors in the retrieved $k_{476}(0-1 \mathrm{~km})$ and $k_{354}(0-1 \mathrm{~km})$ due to the choice of a priori conditions were estimated to be as small as $<9 \%$, as mentioned above.

For 354 and $476 \mathrm{~nm}$, vertical profiles of the sensitivity of the MAX-DOAS $\mathrm{O}_{4}$ measurements to $k, \mathrm{~d}(\Delta \mathrm{SCD}) / \mathrm{d} k$, are shown in Figs. $6 \mathrm{~b}$ and $\mathrm{c}$, respectively. These profiles are for $\mathrm{SZA}=50^{\circ}$. The decreasing measurement sensitivity with altitude is evident. Moreover, the measurement sensitivity is smaller at $354 \mathrm{~nm}$ than at $476 \mathrm{~nm}$. Thus, altitude and wavelength dependencies in the measurement sensitivity can explain the observed tendencies of the differences between MAX-DOAS and lidar data. The observed tendencies have 

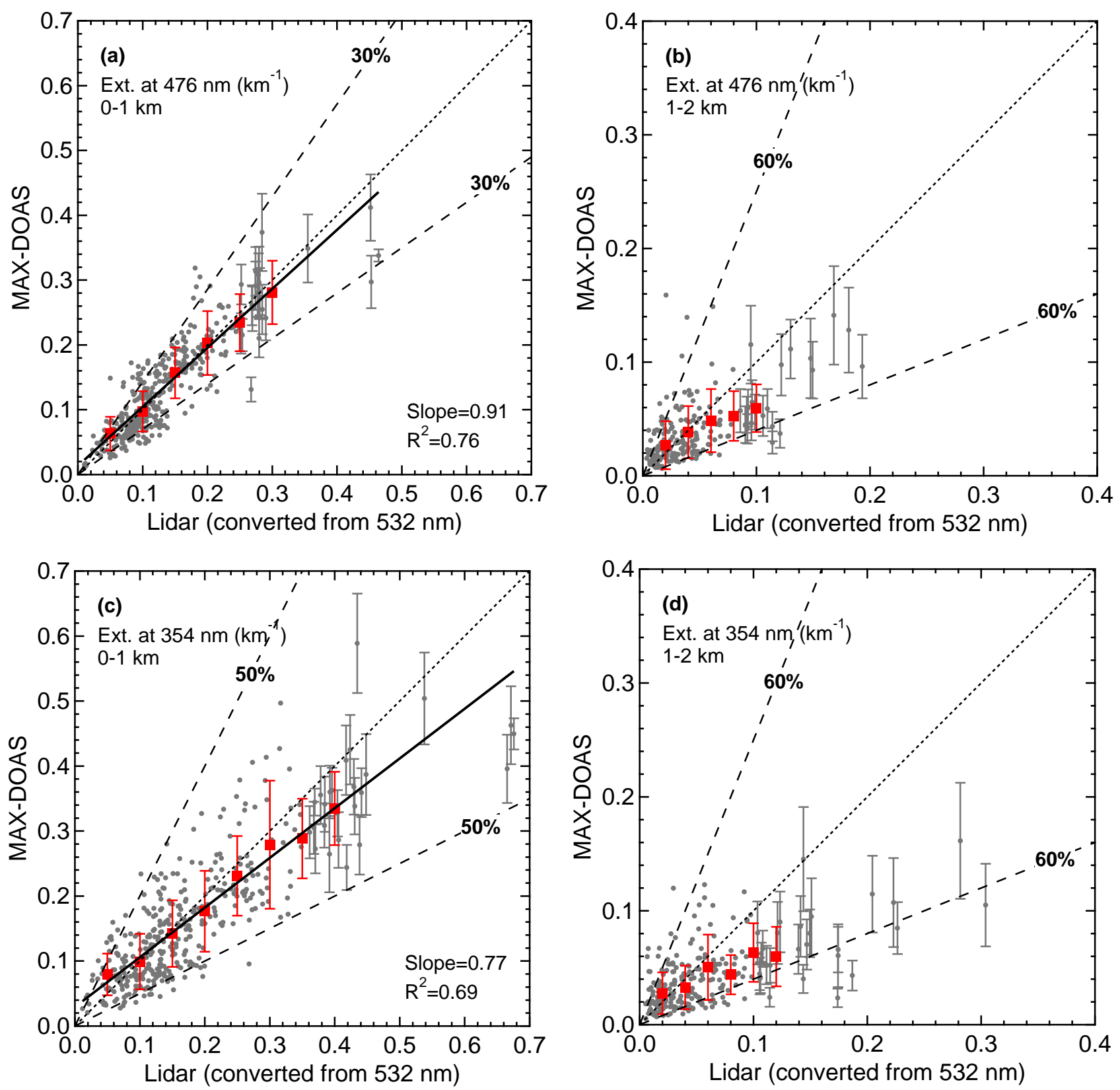

Fig. 3. Correlations between MAX-DOAS and lidar aerosol extinction coefficients at $476 \mathrm{~nm}$ for layers of (a) $0-1$ and (b) $1-2 \mathrm{~km}$. The same correlations but for $354 \mathrm{~nm}$ are shown in (c) and (d). Red symbols indicate the averages of the original MAX-DOAS values (gray) for each bin of the lidar data. Error bars represent $1 \sigma$ standard deviations. For the original MAX-DOAS data, uncertainty estimated from the retrieval covariance matrix is shown only for large lidar values for clarity. Solid lines in (a) and (c) represent the linear least-squares fit to the original data before binning.

also been explained with a simulation by Frieß et al. (2006). They investigated four absorption bands of $\mathrm{O}_{4}$ peaked around $360,477,577$, and $630 \mathrm{~nm}$ and argued that the highest sensitivity to aerosols should occur at 630 and $577 \mathrm{~nm}$, followed by 477 and $360 \mathrm{~nm}$. This should be a result of the higher transparency of the atmosphere leading to better geometric enhancements at longer wavelengths. In addition, the largest cross section occurs at $577 \mathrm{~nm}$, followed by 630,477 , and $360 \mathrm{~nm}$ (Frieß et al., 2006). It is therefore reasonable to ex- pect that better aerosol retrieval performance can be achieved using absorption bands around 577 or $630 \mathrm{~nm}$ compared to those around 477 and $360 \mathrm{~nm}$, which have been used in the present work. Note that this is only the case when analyzing a single absorption band, while Frieß et al. (2006) have proposed to analyze multi-wavelength absorptions together for better performance, compared to the use of a single wavelength. 

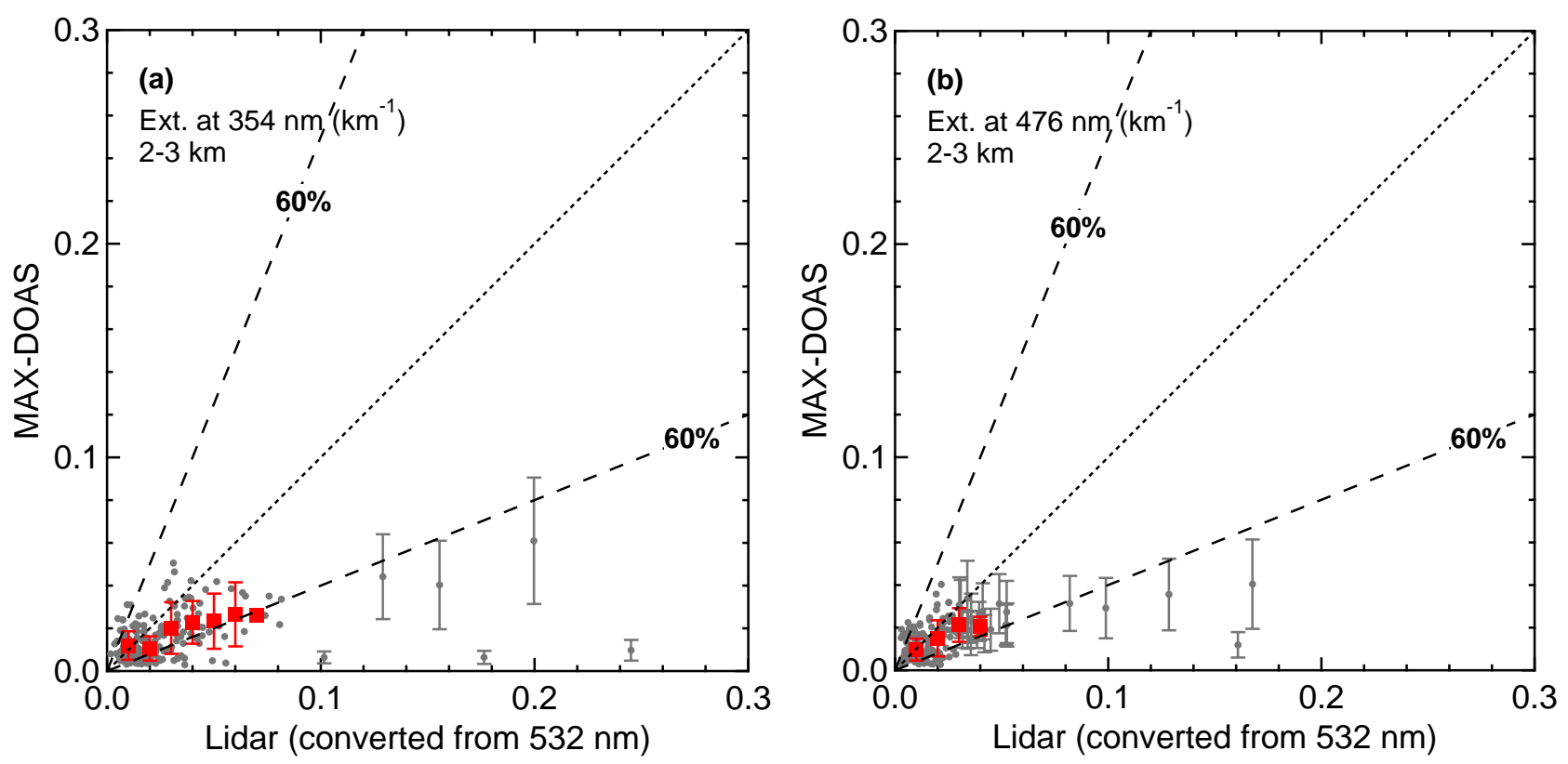

Fig. 4. Same as Fig. 3, but for the aerosol extinction coefficient at (a) 354 and (b) $476 \mathrm{~nm}$ for the layer at 2-3 km.
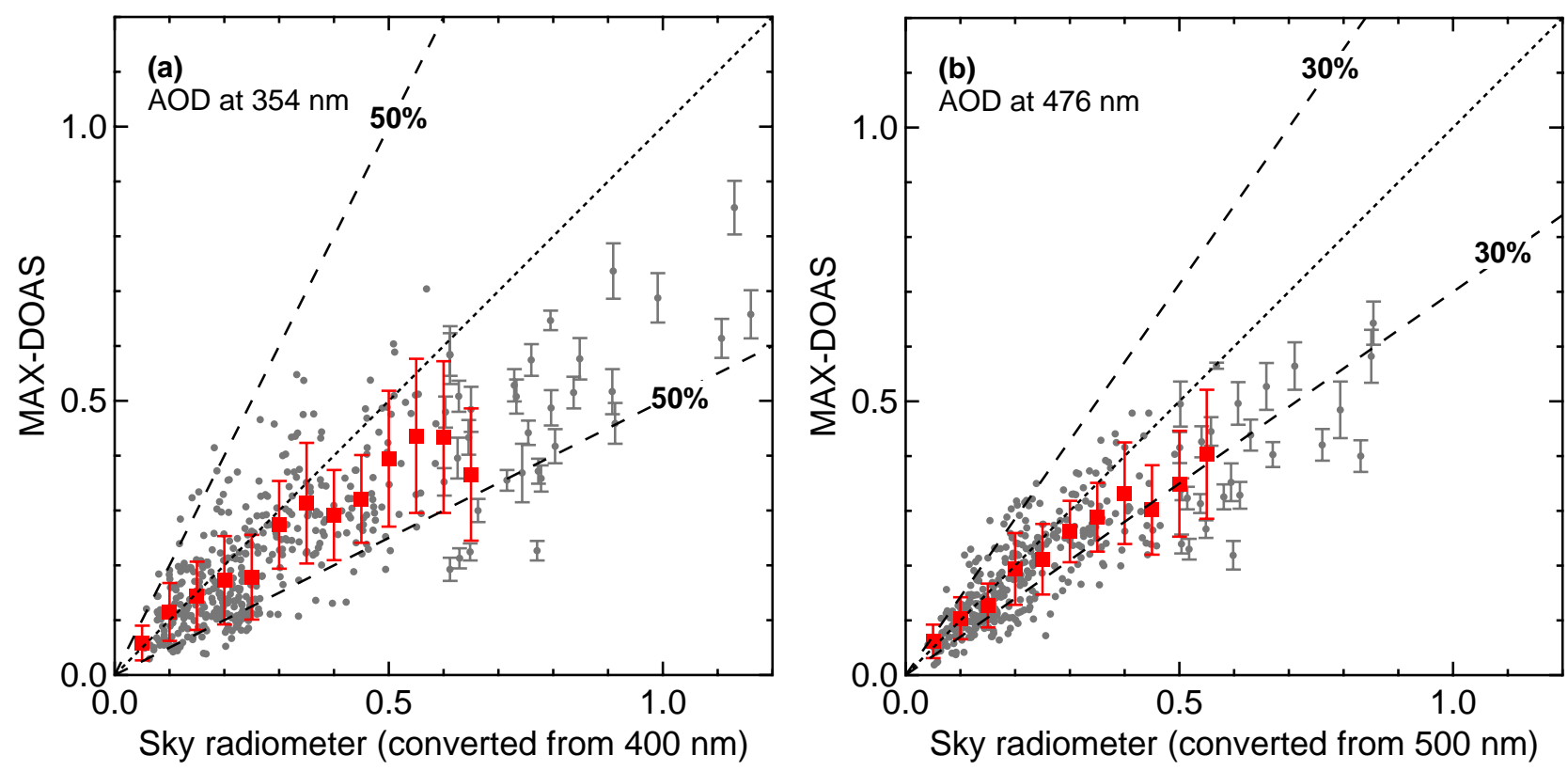

Fig. 5. Same as Fig. 3, but for the aerosol optical depth at (a) 354 and (b) $476 \mathrm{~nm}$.

In the present study we have analyzed $\mathrm{O}_{4}$ absorption bands at 354 and $476 \mathrm{~nm}$ individually, not combined as a single inversion problem. However, it is worth investigating the internal consistency between MAX-DOAS $k_{354}(0-1 \mathrm{~km})$ and $k_{476}(0-1 \mathrm{~km})$ values, both of which have shown better agreement with lidar data than at other altitudes (Fig. 3). Figure 7 shows correlations between the MAX-DOAS $k_{354}(0-1 \mathrm{~km})$ and $k_{476}(0-1 \mathrm{~km})$ values. Also shown are the correlations between aerosol optical depths at 354 and $476 \mathrm{~nm}$ derived from sky radiometer measurements. As expected, values at $354 \mathrm{~nm}$ are systematically greater than at $476 \mathrm{~nm}$ for both MAX-DOAS and sky radiometer data. The slopes of the linear regression are $1.25 \pm 0.03$ and $1.40 \pm 0.01$ for MAXDOAS and sky radiometer measurements, respectively. The corresponding $\alpha$ values were estimated to be $0.75 \pm 0.08$ and $1.14 \pm 0.02$. This may suggest that the $\alpha$ derived from MAXDOAS was underestimated, but more work is needed to interpret the difference, with a consideration of the different 


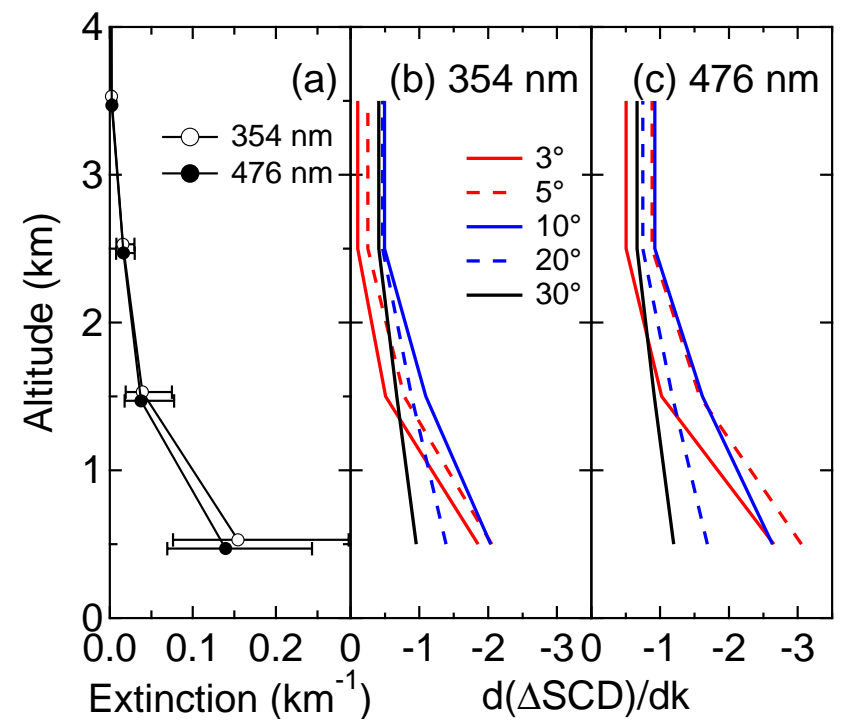

Fig. 6. (a) Median profiles of the retrieved aerosol extinction coefficients at $354 \mathrm{~nm}$ (open symbols) and $476 \mathrm{~nm}$ (solid symbols) for the period from 1 November 2006 to 16 March 2007. Error bars represent the central $67 \%$ of the ranges. (b) and (c) Profiles of the sensitivity of the MAX-DOAS $\mathrm{O}_{4} \triangle \mathrm{SCD}$ measurement (at SZA $=50^{\circ}$ ) to the aerosol extinction coefficient $(k), \mathrm{d}(\Delta \mathrm{SCD}) / \mathrm{d} k$, are shown for 354 and $476 \mathrm{~nm}$, respectively. Different lines show the measurement sensitivities for different elevation angles. The units are $10^{45}$ molecules ${ }^{2} \mathrm{~cm}^{-5} \mathrm{~km}$. Note that the $\mathrm{x}$ axis is reversed in (b) and (c).

altitude ranges measured by MAX-DOAS and the sky radiometer. However, it is interesting to note that the MAXDOAS $\alpha$ value has been derived from $k(0-1 \mathrm{~km})$ values, suggesting that MAX-DOAS is capable of deriving $\alpha$ below $1 \mathrm{~km}$.

We found that the correlation coefficient $\left(R^{2}\right)$ for MAXDOAS $k(0-1 \mathrm{~km})$ data is as high as 0.83 (Fig. 7), although retrievals have been done separately for 354 and $476 \mathrm{~nm}$. In particular, the scatter of the correlations is much smaller than that anticipated from the $50 \%$-range of $k_{354}(0-1 \mathrm{~km})$ and the $30 \%$-range of $k_{476}(0-1 \mathrm{~km})$, which are shown with error bars in Fig. 7. These results confirm that the uncertainty in the MAX-DOAS aerosol data has been well quantified using comparisons with lidar data in this study and can be regarded as upper-limit estimates. Also, it is suggested that part of the differences in comparison with the lidar should have come from the uncertainty in the lidar data and the sampling of different air masses. While MAX-DOAS measurements are thus expected to provide aerosol datasets useful for quantitative studies, an improvement of this technique, for example, by utilizing the $\mathrm{O}_{4}$ absorption at longer wavelengths, is highly desirable.

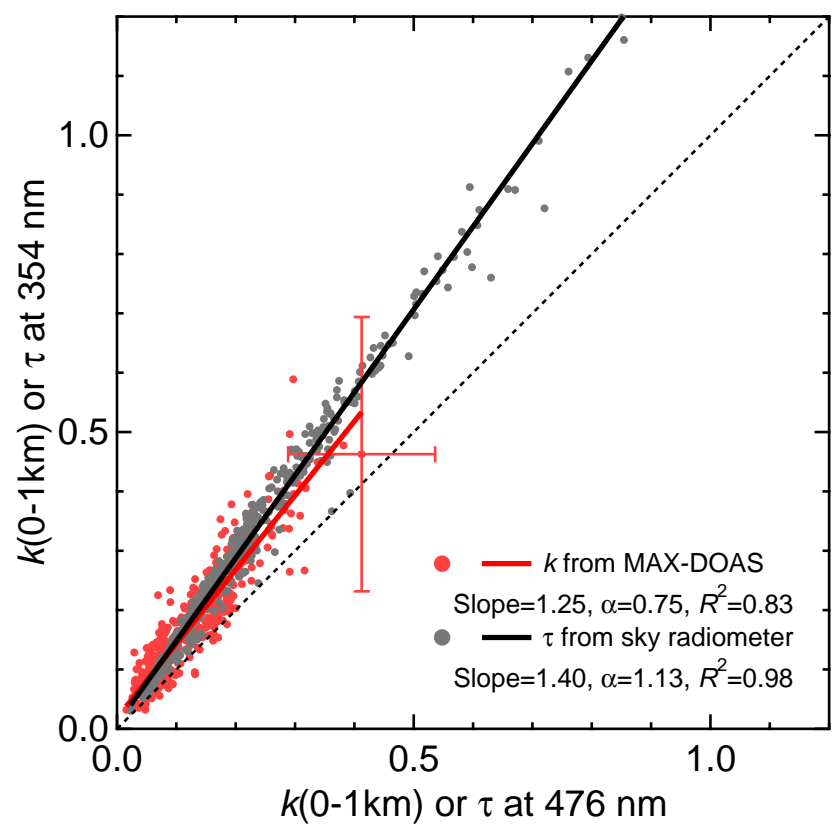

Fig. 7. Correlations between MAX-DOAS aerosol extinction coefficients $(0-1 \mathrm{~km})$ at 354 and $476 \mathrm{~nm}$ (red symbols). Error bars represent $50 \%$ - and $30 \%$-uncertainties estimated from comparisons with the lidar data for 354 and $476 \mathrm{~nm}$, respectively. Correlations between sky radiometer aerosol optical depths at 354 and $476 \mathrm{~nm}$ (gray symbols) are superimposed. The linear least-square fits to MAX-DOAS and sky radiometer data are shown by red and black lines, respectively. The slope of the line and the Ångström exponent $(\alpha)$ calculated from the slope are given.

\section{Conclusions}

To establish a quantitative basis for MAX-DOAS aerosol measurements, aerosol extinction coefficient vertical profiles were retrieved at two wavelengths, $354 \mathrm{~nm}\left(k_{354}\right)$ and $476 \mathrm{~nm}$ $\left(k_{476}\right)$, from spectra measured by MAX-DOAS at Tsukuba, Japan. A robust comparison of MAX-DOAS aerosol extinction profiles with those measured by lidar has been done for more than 4 months between 1 November 2006 and 16 March 2007. The retrieved $k_{476}$ values for the layer at $0-1 \mathrm{~km}$ (1-2 km) generally agreed with the lidar data to within $30 \%$ (60\%), confirming the results of Irie et al. (2008a) that the uncertainty is less than $30 \%$ (60\%) based on comparisons using only two months of data. On the other hand, agreement for $k_{354}$ values at $0-1 \mathrm{~km}$ was within $50 \%$. Thus, we found that uncertainty in MAX-DOAS aerosol extinction data is smaller at a longer wavelength and at lower altitudes (in the case that the instrument is located near the surface). At the upper layers, MAX-DOAS $k_{354}$ and $k_{476}$ values tend to be closer to the a priori at greater lidar $k$ values, resulting in underestimation. This is supported by the fact that a similar underestimation was seen in the comparison between aerosol optical depths obtained from MAX-DOAS and sky radiometer measurements. These dependencies of the systematic differences on 
wavelength and altitude were, however, well characterized by the higher sensitivity of the $\mathrm{O}_{4}$ differential slant column measurement to aerosols, $\mathrm{d}(\triangle \mathrm{SCD}) / \mathrm{d} k$, at the longer wavelength. The value of $\mathrm{d}(\triangle \mathrm{SCD}) / \mathrm{d} k$ was also greater at lower altitudes. Thus, uncertainty in MAX-DOAS aerosol data was quantified, and the cause leading to systematic errors was identified, showing that MAX-DOAS measurements are suitable for quantitative studies. For better performance, an improvement to this technique, for example, by utilizing the $\mathrm{O}_{4}$ absorption at longer wavelengths, is highly desirable.

Acknowledgements. This work was supported by the Global Environment Research Fund (B-051, C-081, and S-7) of the Ministry of the Environment, Japan. This work was supported by the Ministry of Education, Culture, Sports, Science and Technology (MEXT). This work was supported by Japan EOS (Earth Observation System) Promotion Program of the Ministry of Education, Culture, Sports, Science and Technology (MEXT).

Edited by: M. Van Roozendael

\section{References}

Aoki, K. and Fujiyoshi, Y.: Sky radiometer measurements of aerosol optical properties over Sapporo, Japan, J. Meteorol. Soc. Jpn., 81, 3, 493-513, 2003.

Frieß, U., Monks, P. S., Remedios, J. J., Rozanov, A., Sinreich, R., Wagner, T., and Platt, U.: MAX-DOAS $\mathrm{O}_{4}$ measurements: A new technique to derive information on atmospheric aerosols: 2. Modeling studies, J. Geophys. Res., 111, D14203, doi:10.1029/2005JD006618, 2006.

Greenblatt, G. D., Orlando, J. J., Burkholder, J. B., and Ravishankara, A. R.: Absorption measurements of oxygen between 330 and 1140 nm, J. Geophys. Res., 95(11), 18577-18582, 1990.

Heckel, A., Richter, A., Tarsu, T., Wittrock, F., Hak, C., Pundt, I., Junkermann, W., and Burrows, J. P.: MAX-DOAS measurements of formaldehyde in the Po-Valley, Atmos. Chem. Phys., 5, 909918, 2005, http://www.atmos-chem-phys.net/5/909/2005/.

Hendrick, F., Van Roozendael, M., Kylling, A., Petritoli, A., Rozanov, A., Sanghavi, S., Schofield, R., von Friedeburg, C., Wagner, T., Wittrock, F., Fonteyn, D., and De Mazière, M.: Intercomparison exercise between different radiative transfer models used for the interpretation of ground-based zenith-sky and multiaxis DOAS observations, Atmos. Chem. Phys., 6, 93-108, 2006, http://www.atmos-chem-phys.net/6/93/2006/.

Hönninger, G., von Friedeburg, C., and Platt, U.: Multi axis differential optical absorption spectroscopy (MAX-DOAS), Atmos. Chem. Phys., 4, 231-254, 2004,

http://www.atmos-chem-phys.net/4/231/2004/.

Inomata, S., Tanimoto, H., Kameyama, S., Tsunogai, U., Irie, H., Kanaya, Y., and Wang, Z.: Technical Note: Determination of formaldehyde mixing ratios in air with PTR-MS: laboratory experiments and field measurements, Atmos. Chem. Phys., 8, 273284, 2008, http://www.atmos-chem-phys.net/8/273/2008/.

IPCC: Climate Change 2007: The physical science basis, Contribution of working group I to the fourth assessment report of the Intergovernmental Panel on Climate Change, edited by: Solomon, S., Qin, D., Manning, M., Chen, Z., Marquis, M., Averyt, K.
B., Tignor, M., and Miller, H. L.: Cambridge University Press, Cambridge, United Kingdom and New York, NY, USA, 996 pp., 2007.

Irie, H., Kanaya, Y., Akimoto, H., Iwabuchi, H., Shimizu, A., and Aoki, K.: First retrieval of tropospheric aerosol profiles using MAX-DOAS and comparison with lidar and sky radiometer measurements, Atmos. Chem. Phys., 8, 341-350, 2008a, http://www.atmos-chem-phys.net/8/341/2008/.

Irie, H., Kanaya, Y., Akimoto, H., Tanimoto, H., Wang, Z., Gleason, J. F., and Bucsela, E. J.: Validation of OMI tropospheric $\mathrm{NO}_{2}$ column data using MAX-DOAS measurements deep inside the North China Plain in June 2006: Mount Tai Experiment 2006, Atmos. Chem. Phys., 8, 6577-6586, 2008b, http://www.atmos-chem-phys.net/8/6577/2008/.

Iwabuchi, H.: Efficient Monte Carlo methods for radiative transfer modeling, J. Atmos. Sci., 63(9), 2324-2339, 2006.

Kurucz, R. L., Furenlid, I., Brault, J., and Testerman, L.: Solar flux atlas from 296 to 1300 nm, Natl. Sol. Obs., Sunspot, New Mexico, 240 pp., 1984.

Leigh, R. J., Corlett, G. K., Frieß, U., and Monks, P. S.: Concurrent multiaxis differential optical absorption spectroscopy system for the measurement of tropospheric nitrogen dioxide, Appl. Optics, 45(28), 7504-7518, 2006.

Liu, X., Chance, K., Sioris, C. E., Spurr, R. J. D., Kurosu, T. P., and Martin, R. V.: Ozone profile and tropospheric ozone retrievals from the Global Ozone Monitoring Experiment: Algorithm description and validation, J. Geophys. Res., 110, D20307, doi:10.1029/2005JD006240, 2005.

Nakajima, T., Tonna, G., Rao, R., Boi, P., Kaufman, Y., and Holben, B.: Use of sky brightness measurements from ground for remote sensing of particulate polydispersions, Appl. Optics, 35(15), 2672-2686, 1996.

Platt, U.: Differential optical absorption spectroscopy (DOAS), Air Monitoring by Spectroscopic Techniques, edited by: Sigrist, M. W., John Wiley\&Sons, Inc., New York, 127, 27-84, 1994.

Rodgers, C. D.: Inverse methods for atmospheric sounding: Theory and practice, Ser. Atmos. Oceanic Planet. Phys., 2, edited by: Taylor, F. W., World Sci., Hackensack, N.J., 2000.

Shimizu, A., Sugimoto, N., Matsui, I., Arao, K., Uno, I., Murayama, T., Kagawa, N., Aoki, K., Uchiyama, A., and Yamazaki, A.: Continuous observations of Asian dust and other aerosols by polarization lidars in China and Japan during ACE-Asia, J. Geophys. Res., 109, D19S17, doi:10.1029/2002JD003253, 2004.

Sinreich, R., Volkamer, R., Filsinger, F., Frieß, U., Kern, C., Platt, U., Sebastián, O., and Wagner, T.: MAX-DOAS detection of glyoxal during ICARTT 2004, Atmos. Chem. Phys., 7, 1293-1303, 2007, http://www.atmos-chem-phys.net/7/1293/2007/.

Wagner, T., Dix, B., von Friedeburg, C., Frieß, U., Sanghavi, S., Sinreich, R., and Platt, U.: MAX-DOAS $\mathrm{O}_{4}$ measurements: A new technique to derive information on atmospheric aerosols - Principles and information content, J. Geophys. Res., 109, D22205, doi:10.1029/2004JD004904, 2004.

Wagner, T., Burrows, J. P., Deutschmann, T., Dix, B., von Friedeburg, C., Frieß, U., Hendrick, F., Heue, K.-P., Irie, H., Iwabuchi, H., Kanaya, Y., Keller, J., McLinden, C. A., Oetjen, H., Palazzi, E., Petritoli, A., Platt, U., Postylyakov, O., Pukite, J., Richter, A., van Roozendael, M., Rozanov, A., Rozanov, V., Sinreich, R., Sanghavi, S., and Wittrock, F.: Comparison of box-airmass-factors and radiances for Multiple-Axis Differential Opti- 
cal Absorption Spectroscopy (MAX-DOAS) geometries calculated from different UV/visible radiative transfer models, Atmos. Chem. Phys., 7, 1809-1833, 2007,

http://www.atmos-chem-phys.net/7/1809/2007/.
Wittrock, F., Oetjen, H., Richter, A., Fietkau, S., Medeke, T., Rozanov, A., and Burrows, J. P.: MAX-DOAS measurements of atmospheric trace gases in Ny-Ålesund - Radiative transfer studies and their application, Atmos. Chem. Phys., 4, 955-966, 2004, http://www.atmos-chem-phys.net/4/955/2004/. 